\title{
Ensino de História, Formação de Professores(as) e PIBID: o uso de HQs e Cartoons como possibilidade didático- pedagógico nas aulas de história ${ }^{1}$
}

History Teaching, Teacher Training and PIBID: the use of comic books and cartoons as a didactic-pedagogical possibility in history classes

Antonio Alves Bezerra José Augusto Ferreira da Silva Roberta dos Santos Sodó

Resumo: $O$ artigo discute a formação inicial e continuada de professores(as) de História à luz do Programa Institucional de Bolsa de Iniciação à Docência - PIBID, utilizando-nos de reflexões e diálogos com o aporte teórico sobre a formação do/a professor(a)-historiador(a). Assim, focamos em uma das ações do subprojeto/História/UFAL (2015/2018), com destaque para a utilização de HQs e cartoons nas aulas de história enquanto metodologia de ensino na Educação Básica. Dialogaremos com a legislação e bibliografia sobre o PIBID, referenciais teóricos acerca da formação de professores e trechos de Relatórios de atividades desenvolvidas por estudantes de Iniciação à Docência e professores(as) supervisores(as) de área, chegando-se, assim, a conclusão das possibilidades que o Programa revela sobre a formação inicial e continuada de professores(as) de História não apenas no estado de Alagoas, mas no país.

Palavras-chave: PIBID/História. Docência. Linguagem diferenciada. Ensino de História.

Abstract: The article discusses the initial and continuing training of History teachers in the light of the Institutional Program for Teaching Initiation Scholarships - PIBID, using reflections and dialogues with the theoretical contribution on the training of the teacherhistorian. Thus, we focused on one of the actions of the subproject / History / UFAL (2015/2018), with emphasis on the use of comics and cartoons in history classes as a teaching methodology in Basic Education. We will dialogue with the legislation and bibliography on PIBID, theoretical references about teacher training and excerpts from Activity reports developed by Undergraduate Teaching students and area supervising teachers, thus reaching the conclusion of the possibilities that the Program reveals on the initial and continuing education of History teachers not only in the state of Alagoas, but in the country.

Keywords: PIBID/History. Teaching. Differentiated languages. History Teaching.

\section{Introdução}

O PIBID/História da UFAL se configura em uma importante ação de formação inicial e continuada de professores(as) no estado de Alagoas. Este tem assumido protagonismo entre alguns dos programas de formação de

\footnotetext{
${ }^{1} \mathrm{O}$ presente artigo é o resultado das Ações de ensino e aprendizagem desenvolvidas no âmbito do Projeto Institucional da UFAL com fulcro no subprojeto PIBID/História do Campus A.C. Simões, orientado pelo EDITAL № 061/2013 da CAPES
} 
professores(as) no âmbito das escolas de Educação Básica do estado. Enquanto Programa de Incentivo à Docência do governo federal, o PIBID foi instituído no final da primeira década do século XXI pelo Decreto de $n^{0} 7.219$, sancionado pelo então presidente da República Luiz Inácio Lula da Silva com base na Portaria $n^{\circ}$ 122/2009, que normatizou o Programa de Bolsas de Iniciação à Docência ${ }^{2}$ no âmbito da Coordenação de Aperfeiçoamento de Pessoal de Nível Superior (CAPES).

Após três anos de sua regulamentação, o Programa teve suas normas aperfeiçoadas e atualizadas por meio da Portaria de $n^{\circ}$ 096/2013, que dentre outras questões buscou definir para os/as bolsistas participantes algumas linhas específicas de atuação. A título de exemplificação, o $\operatorname{artigo} 2^{\circ}$ da referida Portaria colocou em relevo que o PIBID enquanto Programa de formação e aperfeiçoamento da formação inicial e continuada de professores(as) financiados pela CAPES, partia da premissa de promover a formação de professores(as) para atender os anseios da Educação Básica em todo o país (BEZERRA, 2020). Em sua essência, o Programa busca:

Incentivar a formação de docentes em nível superior para a Educação Básica; contribuir para a valorização do magistério; elevar a qualidade da formação inicial de professores nos cursos de licenciatura, promover a integração entre educação superior e educação básica; inserir os licenciandos no cotidiano de escolas da rede pública de educação (CAPES, 2013, s.p.).

Apesar das críticas pontuais ao Programa (PIMENTA; LIMA, 2019, p. 7), consideramos que o mesmo tem buscado desenvolver atividades teóricas e práticas no âmbito das salas de aulas com nível de excelência aceitável, quando nos reportamos a uma política de formação inicial e continuada de professores(as) para Educação Básica no país. Embora, ainda em número incipiente de bolsistas contemplados(as) pelo Programa nas edições anteriores e nas mais recentes, as autoras destacam que em 2013 o PIBID atendeu cerca

\footnotetext{
2 Segundo Bezerra (2018), o/a professor(a) coordenador(a) de área é um(a) docente do curso de licenciatura que submete o subprojeto do curso ao projeto institucional da universidade, tendo em vista as demandas sociais oriundas das escolas públicas indicadas a participarem do PIBID e as demandas do próprio curso proponente do subprojeto. O/a professor(a) supervisor(a) é o/a responsável pela supervisão e orientação dos/as licenciandos(as) nas escolas. A adesão ao Programa é facultativa e a inserção dá-se por meio de processo seletivo simplificado definido em Portaria da CAPES.
} 
de "5,38\% dos estudantes matriculados em cursos de licenciatura no país" (Ibid.), para nós, o PIBID tem ressignificado o curso de Licenciatura em História da UFAL no que tange a formação de professores(as) para a disciplina de história na Educação Básica. Desdobrando-se em projetos de pesquisa para fins de Trabalhos de Conclusão de Curso (TCCs) e projetos de mestrados desenvolvidos no PPGH/UFAL e outros Programas de Pós-graduação no país, realidade até então não evidenciada antes da implementação do Programa nesta instituição.

Nota-se, ainda, que a maioria dos/as estudantes de história do período noturno (no caso da UFAL) são chefes de famílias que residem nos interiores de Alagoas e já possuem outras atividades laborais com remuneração. Em tempos outros, dado a instabilidade da profissão docente no estado, optaram por outras funções remuneradas diferentes de uma bolsa de estudos e/ou de pesquisa que tem tempo de início e final, vinculados a sua formação superior. Muitas vezes motivados(as) tão somente pela premissa de possuírem um diploma em nível superior, enfraquecendo, assim, o curso de formação de professores(as) na universidade, conjuntamente com à própria docência na Educação Básica, dado aos percalços e desvalorização da docência não apenas neste estado, mas no país como um todo.

De todo modo, notamos que os/as bolsistas do Programa, particularmente os/as de História (curso noturno da UFAL), têm tido a oportunidade de vivenciar experiências didáticas além daquelas legitimadas pelo Estágio Supervisionado Curricular Obrigatório, ampliando, assim, seus olhares acerca do seu futuro local de trabalho, ao buscar uma identificação maior com a docência, um dos objetivos do Programa em apreço. Não obstante, destaca-se que: Nóvoa (2013) pondera que,

É preciso termos consciência de que os problemas da
educação e dos professores não serão resolvidos apenas no
interior das escolas. É preciso um trabalho político, uma maior
presença dos professores da academia no debate público, uma
consciência clara da importância da educação para as
sociedades do século XXI (NÓVOA, 2013, p. 209).

O excerto leva-nos a refletir que as ações pedagógicas implementadas pelo PIBID em diálogo com o Projeto Político Pedagógico do Curso de História 
(UFAL), têm propiciado aos graduandos(as) em história uma melhor adesão ao trabalho docente, para além das ações didático-pedagógicas do currículo do curso. O PIBID e outros Programas como PIBIC, servem também de suporte para manutenção dos/as estudantes no curso, que em sua maioria, possuem rendas familiares muito baixas, que inviabiliza a sua permanência fora de casa para estudar. ${ }^{3}$

Nesse sentido, compreendemos que o Programa desvela oportunidades aos estudantes de identificação com a docência, com o seu futuro local de trabalho, somando-se as ações até então já desenvolvidas pelo Estágio Supervisionado Obrigatório, construindo pontes para o enfrentamento dos desafios inerentes aos fazeres da docência. Nesse ínterim, compreendemos ainda, que o PIBID tem sido um espaço privilegiado "para implementar e fortalecer ações efetivas de formação de professores(as), ampliando experiências significativas sobre a relação universidade e escola pública" (RUBO et al., 2015, p. 160). Corroborando as preocupações de Nóvoa quanto ao futuro da docência,

Nas sociedades contemporâneas, o prestígio de uma profissão mede-se, em grande parte, pela sua visibilidade social. No caso dos professores, estamos mesmo perante a uma questão decisiva, pois a sobrevivência da profissão depende da qualidade do trabalho interno nas escolas, mas também da sua capacidade de intervenção no espaço público da educação (NÓVOA, 2013, p. 208).

No contexto de reflexões acerca dos fazeres e saberes da docência em história, o texto procura demonstrar como o uso de diferentes linguagens no ensino pode colaborar para aprendizagem histórica de estudantes da Educação Básica. Trata-se de aulas-oficinas realizadas com estudantes de $3^{\text {os }}$ anos do Ensino Médio, de uma escola da rede regular de ensino do estado de Alagoas. Em face disso, o escrito desvela uma das ações do Pibid integrada à

3 A Editora da UFAL (EDUFAL), lançou em 2020 um ebook referente à pesquisa do "Perfil socioeconômico e cultural dos(as) estudantes da UFAL", realizada pela Pró-Reitoria Estudantil (PROEST) da universidade. Foi demonstrado pela pesquisa que a UFAL acompanha uma característica nacional quanto ao perfil socioeconômico de seus/suas estudantes, quando $80,2 \%$ possuem renda familiar per capita de até um e meio salário mínimo (UFAL, 2020). 
aula de História ministrada pela então professora supervisora de área, cujo tema da sequência era Guerra Fria. ${ }^{4}$

Para tanto, elaborou-se uma pontual intervenção dos(as) bolsistas, utilizando-se de uma aula para elucidar do ponto de vista teórico, o enquadramento anticomunista em produções culturais dos EUA, levadas a efeito durante os 45 anos de Guerra Fria (BUTLER, 2015). As mesmas produções continuam circulando no tempo presente, sob novas molduras, através de equipamentos de comunicação de massa que vão de encontro, sobretudo, ao público adolescente. Nesse sentido, buscou-se problematizar as "operações de poder" que envolvem, em especial, algumas Histórias em Quadrinhos (HQs) que retratam de forma explícita ou subliminar contornos de uma visão sobre o "outro" soviético. Difundidas e adaptadas nas últimas décadas, as HQs carregam forte carga ideológica, que sob um olhar mais crítico, podem ser interpretadas numa perspectiva histórica de lutas políticas e ideológicas.

Do ponto de vista da didática do ensino de história, a atividade consistiu em desvelar junto aos estudantes, que existem outras formas de explicar a Guerra Fria e seu contexto histórico, sem precisar recorrer tão somente a explanações geopolíticas tradicionais. Nesse aspecto, utilizamos as HQs Super Man (2003) e X-Men (1963), conjuntamente, através do cartoon Os Simpsons (1992), apresentamos o "terror soviético" no imaginário norte-americano, utilizando a crítica apresentada pelo cartoon como contextualizadora de acontecimentos importantes. A título de exemplo, o boicote soviético das Olimpíadas de 1984 e o uso do conflito como margem para o lucro empresarial nos EUA. A ideia de usar diferentes recursos, neste caso as HQs e cartoons, para explicar temas por vezes demasiadamente complexos como a Guerra

\footnotetext{
${ }^{4}$ Guerra Fria (1947-1991) é o nome que se adotou popularmente para designar o período de conflito entre Estados Unidos da América (EUA) e União das Repúblicas Socialistas Soviéticas (URSS). Essas nações emergiram pós Segunda Guerra Mundial (1939-1945) como superpotências político-econômicas. Segundo Hobsbawm, "Gerações inteiras se criaram à sombra de batalhas nucleares globais que, acreditava-se firmemente, podiam estourar a qualquer momento, e devastar a humanidade" (1995, p. 178). Para Mészáros, a "guerra fria" é a forma racionalizada da "carga sempre crescente do rearmamento contínuo" para a "produtividade" do capital (2011, p. 333).
} 
Fria, foi bem recebida pela maioria dos/as estudantes, uma vez que as aulas se tornaram um pouco mais atrativas e compatíveis com as suas vivências.

\section{As diferentes linguagens do ensino de história e o "enquadramento" de algumas representações}

Acreditamos que o estudo do passado deve despertar para a responsabilidade ética necessária à vida em sociedade. Está além, portanto, da internalização de datas e de acontecimentos entendidos como fundamentais no curso das realizações humanas. Um processo de aprendizagem histórica que tematize a guerra, por exemplo, deveria insistir na dimensão das "operações de poder" que "enquadram" de maneira diferencial estar sujeito a violência (BUTLER, 2015).

Em face disso, identificamos nas HQs Super Man (2003) e X-Men (1963), o "enquadramento" do "inimigo vermelho" como um alvo a ser destruído, em nome da conservação de "vidas que importam mais", nesse caso a de norte-americanos(as). Tais "operações" não se limitaram a períodos de guerra ou na relação entre nações, elas têm seu equivalente nacional quando da desassistência e violação de direitos de grupos considerados "minoritários". De forma regional e global, assistimos a violência empreendida na tentativa de subjugar grupos étnicos, pobres, mulheres, LGBTQIA+, imigrantes e negros(as). O "enquadramento" da aparição desses grupos poderá fazer com que nos sensibilizemos com sua condição, ou o oposto.

$\mathrm{Na}$ medida em que nos relacionamos aprendemos formas de olhar o "outro", isso significa, que de maneira constante os "enquadramentos" estão se (re)produzindo. Segundo Butler, eles "não só organizam a experiência visual como também geram ontologias específicas do sujeito" (2015, p. 17). Desse modo, todos os fragmentos do passado como parte dessa socialização dos indivíduos, podem se constituir em objetos de reflexão para nossa orientação (RÜSEN, 2010).

As HQs aqui trabalhadas operam através de uma construção narrativa reguladora da comoção. Para que sua trama faça sentido, devemos possuir disposições éticas que diferenciam o bem e o mal, os humanos e os não 
humanos. Estas noções em contexto de aulas de história na Educação Básica, servirão para problematizar o dualismo presente nas HQs e de modo geral na disputa entre norte-americanos (mocinhos) e soviéticos (vilões). São a partir delas que se justificaram as perdas humanas dos dois lados, daqueles que morreram defendendo o que é "bom", e dos inimigos que não podem ser considerados como perdas.

O ensino de história não deveria ficar circunscrito ao texto ou ao livro didático, a uma história apenas de eventos acabados, tampouco tentar transformar os/as estudantes de Educação Básica em "pequenos historiadores", como aponta Bitencourt (2015). A autora explica que as fontes históricas não estão dadas, elas são construídas por historiadores(as), embasados(as) em seus conhecimentos prévios sobre o contexto histórico em que se insere suas pesquisas ou em contextos de produção próprios do fazer história. Trata-se de "'isolar" um corpo, como se faz em física, e em 'desfigurar' as coisas para constituí-las como peças que preencham lacunas de um conjunto, proposto a priori” (CERTEAU, 1892, p. 73). Assim, ao que deve se atentar o/a docente de história é antes a interpretação que o/a estudante faz das diferentes fontes históricas. No caso de documentos não escritos, "identificar como o aluno apreende as imagens e suas representações. As imagens tecnológicas são o real ou as representações do real?" (BITENCOURT, 2005, p. 365).

Trazer a prática essas reflexões engendra uma mudança de postura em relação às fontes históricas e a historiografia. As fontes não teriam o papel de comprovar um único passado ou a de legitimar a fala dos/as docentes. A historiografia se mostra como um campo especializado, dentre outros discursos que mobilizam o passado. O ensino de história procura mostrar que a disciplina é um discurso que, em meio a diversos outros e em conflito com estes, cria ordem para o passado, estabelece formas de sentir e de olhar para o último e, com isso, situa o sujeito num certo presente. O professor de História na escola estabelece as diferenças entre os diversos discursos que se propõem a recriar o passado e o relato historiográfico, discute a especificidade do cinema, da televisão, da literatura e, sobretudo, da historiografia como o espaço mesmo do ofício da produção de representações sobre o passado. (PEREIRA \& SEFFNER, 2008, p. 119). 
Assim, consideramos que o objetivo da história, enquanto parte do currículo da Educação Básica, não é apenas o de transmitir "fatos" acabados de um passado distante, nem é o/a docente de história apenas um/a vulgarizador(a) do conhecimento produzido na academia. Déa Fenelon é assertiva quando nos revela na década de oitenta do século passado, que o ensino de história se encontrava desarticulado, despolitizado, fragmentado, especializado, cada vez mais tomado como prática educativa destinada a desenvolver nos alunos o mito da "memória nacional", com seus ritos e maniqueísmos de violões e heróis (FENELON, 2008, p. 26).

Em contrapartida, buscamos um ensino voltado para a crítica dos "enquadramentos" criados no passado e (re)produzidos no tempo presente. Como determinado grupo social fez significar a sua existência e quais as possibilidades de descobrir por que o fez de tal forma e não de outras? E hoje, quais representações estão sendo criadas a seu respeito? Diante destas inquietações, cabe aos docentes de história junto com os/as estudantes das turmas nas quais ministra aulas, buscar "historicizar as instituições, as políticas, os modelos culturais, os modos de ser e, sobretudo, as identidades" dos sujeitos dentro de determinados recortes espaciais e temporais (PEREIRA \& SEFFNER, 2008, p. 119).

Para isso, o/a professor(a)-historiador(a) deve estar disposto(a) a compreender as mais variadas formas que a sociedade se utilizou como linguagem, negando o uso do livro didático como única fonte. Ampliando-se os horizontes da sala de aula buscando "levar as novas gerações a conhecerem suas próprias determinações, a construir relações de pertencimento a um grupo, a uma história coletiva e a lutas coletivas" (Ibid.).

\section{HQs e Cartoons: possibilidade de ensino e aprendizagem histórica}

A indicação para as intervenções realizadas em salas de aulas junto aos estudantes das turmas acompanhadas pelos(a) autores(a)deveria estar relacionada ao tema programado no calendário letivo pelo/a professor(a) supervisor(a) de área ou professor(a) regente. No período em que a ação do $\mathrm{PIBID/História} \mathrm{foi} \mathrm{planejada,} \mathrm{os/as} \mathrm{estudantes} \mathrm{se} \mathrm{preparavam} \mathrm{para} \mathrm{adentrar} \mathrm{o}$ 
tema Guerra Fria, um clássico dos manuais didáticos das aulas de história nos anos finais do ensino Fundamental e Médio. Com isso, alertamos que a escolha pelo uso de HQs e cartoons enquanto ferramentas didáticas e pedagógicas, se deram com o conhecimento das potencialidades do material para trazer aos estudantes aspectos sobre o período histórico em questão.

A história da popularização dos quadrinhos está entrelaçada a difusão do jornal enquanto ferramenta de comunicação rápida nos meandros entre a segunda metade do século XIX e o início do século XX. Apesar disso, é só com a criação da imagem dos super-heróis que as HQs emplacam enquanto instrumento de comunicação, mas, também, de lazer. São exemplos de sucesso de épocas as revistas do Superman (1938), Batman (1939), Capitão América (1940) e Mad (1952). As histórias e personagens não permaneceram apenas nas revistas, ganharam versões diferentes, a exemplo do cinema e do cartoon, quando emerge a ideia de estes serem veiculados pela televisão. Por seu turno, devemos ainda perceber seus símbolos estampados em roupas e acessórios, cartazes e nos variados produtos de épocas.

Destarte, (ADORNO; HORKHEIMER, 1971), na década de 1940 potencializaram reflexões e debates ao indicar que "o produto das artes e da cultura foram transformados em bens de consumo". Por assim dizer, a Indústria Cultural se encarrega em disseminar o entretenimento para a população sem a preocupação de criticidade, ao contrário, cria um discurso de conformação das relações de trabalho, através do hobby, lazer disponibilizado pela própria indústria, como bem observa os autores:

Se as massas são injustamente difamadas do alto como tais, é também a própria indústria cultural que as transforma nas massas que ela depois despreza, e impede de atingir a emancipação, para qual os próprios homens estariam tão maduros quanto as forças produtivas da época o permitiriam. (ADORNO; HORKHEIMER, 1971, p. 295).

Se por um lado devemos situar os autores Adorno e Horkheimer no seu tempo, período fortemente marcado pela derrocada do nazifascismo na Europa e o surgimento do capitalismo monopolista dos EUA. Por outro, entendemos que o que observaram em torno da disseminação dos discursos por meio da produção cultural de "massa", pode ser utilizado por nós para compreender as 
imagens criadas e veiculadas por HQs e cartoons como poderosas ferramentas ideológicas de produção de consensos sobre a Guerra Fria, perspectiva que adotamos durante nossa ação aqui relatada.

Em face disso, nota-se que os filósofos citados estavam preocupados com as influências da cultura na razão humana, ou na vida econômica e social. Nós, professores(as), por outro lado, reconhecendo a existência ativa do conteúdo produzido pela indústria do entretenimento na vida dos/as estudantes, mobilizamos o potencial histórico e pedagógico deste material para construir junto a estes(as) uma recepção crítica dos valores sobre a sociedade e sua história, que esses meios (re)produzem.

É relevante assinalar sobre a responsabilidade de escolher um material adequado, de acordo com as faixas etárias dos/as estudantes, e, conjuntamente observar as características de cada turma nas quais o/a docente ministra aulas, todas têm suas singularidades. A título de exemplo, consideramos a série de animação Os Simpsons, criada pelo cartunista estadunidense Matthew Groening e transmitida pela primeira vez em 1987. O sitcom satiriza constantemente o american way of life através de situações pseudo-corriqueiras (SANTIAGO, 2009). A linguagem carregada de ironia e humor satirizado de Os Simpsons pode não se adequar a turmas do Ensino Fundamental, além disso, o cartoon não está livre de extensas críticas por manter estereótipos e preconceitos. A polêmica mais recente inclui acusações de racismo em torno da personagem $A p u$, um indiano que vive nos EUA. O modo como se expressa essa personagem, também sua transformação com o passar do tempo, sobretudo, analisando uma séria tão duradoura, é ainda proposta de nosso trabalho enquanto professores(as) de história. Apesar de a intervenção ter se voltado às correlações com a temática da Guerra Fria.

Além de utilizarmos Os Simpsons, fizemos uso também da HQ X-Men, ao exemplificarmos como as disputas de consciência ocorriam no referido período. Por meio da apresentação de slides contendo os materiais por nós selecionados, indicamos aos discentes como no plano cultural, EUA e URSS recorreram a indústria de entretenimento para consolidar e ampliar seus raios de influência. Na perspectiva do historiador Hobsbawm (2016), a história desse 
período foi reunida sob um padrão único: o constante confronto das duas superpotências que emergiram da Segunda Guerra Mundial.

Lançada nos Estados Unidos em 10 setembro de 1963, criada por Stanley Lee e Jack Kirby (criadores de outras HQs de sucesso como Homem Aranha e $\mathrm{O}$ Incrível Hulk), X-Men foi bastante original em seu formato, dentre outros motivos, pelo fato de apresentar um novo modelo de super-heróis. Protagonizam a história humanos com "super-poderes", conhecidos como mutantes $^{5}$, eles(as) são vistos como potenciais ameaças ao humanos "normais", por isso, sofrem perseguições de diversos setores sociais. Perpassa esta $\mathrm{HQ}$ questões de identidade e pertencimento que agitaram as décadas de 50 e 60. Este período é marcado por revoluções comportamentais e reivindicações de direitos sociais, por grupos historicamente subjugados. A exemplo, o conflito interno nos EUA pelos direitos civis de afro-americanos(as), que chegou a momentos de elevada tensão, com várias manifestações, passeatas e assassinatos de líderes do Movimento Negro, como o de Martin Luther King Jr em 1968. ${ }^{6}$ Este foi, provavelmente, o ponto que mais chamou a atenção dos/as estudantes para o debate acerca do tema.

Não há eventos "pós-nascimento" que justifiquem os "super-poderes" dos/as mutantes de X-Men. Eles(as), portanto, já teriam nascido com tais habilidades "sobre-humanas". Entretanto, no decorrer da narrativa torna-se evidente o fato dessas mutações serem provenientes da alta radiação das indústrias nucleares. Esse cenário é compatível com um mundo onde se produzem armas de efeitos aniquiladores, como as usadas pelos EUA ao fim da Segunda Guerra Mundial, contra as cidades japonesas de Hiroshima e Nagasaki. É interessante considerar também o contexto da Guerra Fria, marcado pela corrida armamentista e o medo do confronto direto entre as duas superpotências (URSS x EUA), com uso da energia nuclear. Paralelamente, o conflito social interno pelos direitos civis dos afro-americanos também chegava

\footnotetext{
5 Termo científico empregado para as vítimas com sequelas decorrentes dos bombardeios nucleares em Hiroshima e Nagasaki cuja radiação causa modificações e deformações físicas e genéticas.

${ }^{6}$ Malcon X foi também assassinado, em 21 de fevereiro de 1965.
} 
a momentos de elevada tensão com várias manifestações, passeatas e mortes de líderes do movimento negro, anos mais tarde. ${ }^{7}$

Nascer com habilidades especiais implica em alguns problemas: podemos ter a tendência de rejeitar e temer o desconhecido. Logo, os/as mutantes, por possuírem características "anormais" em relação à "humanidade comum", são rejeitados(as) e perseguidos(as). Nesse sentido, recorremos ao conceito de normal/normalidade ${ }^{8}$, discutido pelo filósofo estadunidense Patrick Hopkins (2009). Segundo o autor, os indivíduos sentem a necessidade de destacar-se em relação ao grupo por meio de habilidades, sejam artísticas ou esportivas, algo que, em geral, o grupo não possa fazer com facilidade. Entretanto, ao mesmo tempo em que desejamos nos destacar dos/as demais, também precisamos ser aparentemente normais para sermos aceitos(as) pelo grupo.

Em síntese, o autor pondera ser um dilema da condição humana: "queremos pertencer e nos destacar. Mas há vários modos de ganharmos destaque, alguns melhores que outros. Alguns indicam às pessoas que somos desejáveis, outros indicam que somos indesejáveis" (HOPKINS, 2009, p. 23).

Partindo desse princípio, podemos destacar uma das mais importantes personagens da $\mathrm{HQ}$, o Professor Charles Xavier (também mutante, com poderes telepáticos, líder dos X-Men e fundador de uma escola para adolescentes mutantes). Ele é um mediador nessa relação de forças, tentando criar mecanismos para uma boa convivência entre mutantes e humanos(as) sem "superpoderes", pois os/as primeiros(as) considerados(as) seres "anormais" pela sociedade, eram discriminados(as) e posteriormente perseguidos(as) pelos(as) segundos(as). Curiosamente, a primeira revista da série trata justamente de um sonho do Professor Xavier, em que humanos(as) e mutantes conviviam pacificamente no mundo todo, apesar de suas diferenças. Nesse ponto, percebemos as referências históricas dentro da $H Q$, pois, como já mencionado, X-Men foi lançada em setembro de 1963 e,

\footnotetext{
${ }^{7}$ Malcon X, assasinado 21 de fevereiro de 1965; Martin Luther King Jr. em 4 de abril de 1968. ${ }^{8}$ HOPINKS, Patrick D. A sedução do normal: Quem não quer ser um mutante? In: IRWIN, W. (coord.). Op. cit., p. 22-23.
} 
anteriormente, no dia 28 de agosto do mesmo ano, Martin Luther King Jr. fez um discurso que se tornou célebre, para cerca de 250 mil pessoas, em Washington DC. Ele iniciou seu discurso com a conhecida frase: "I have a dream" (Eu tenho um sonho).

Não obstante, nesse discurso, o reverendo King, como também era conhecido por ter sido um pastor batista, proclamava que seu maior sonho era viver em uma terra em que pessoas negras e brancas teriam os mesmos direitos e tratar-se-iam com fraternidade. Até mesmo lugares marcados pelo racismo como o estado do Mississipi, seriam transformados em "um oásis de liberdade e justiça". 9

Nesse aspecto, o recorte temporal é os anos de 1950, quando aparece na cena política dos EUA o senador Joseph McCarty. Ele traz à público a ideia de banir todo e qualquer foco comunista, ou formas de pensamento político que remetessem ao socialismo, instaurando, assim, uma perseguição desenfreada às pessoas consideradas comunistas ou simpatizantes de qualquer outra ideologia contrária ao capitalismo, acontecimento histórico chamado de Macartismo. $\mathrm{Na} \mathrm{HQ}$, essa força repressiva estatal foi representada pelo "Projeto Sentinela", desenvolvido pelo antropólogo Bolivar Trask. O mesmo acreditava e temia que os mutantes representassem uma ameaça a humanidade, por indicarem o próximo passo da evolução darwiniana, eles são descritos(as) na narrativa como a espécie Homo Superiors, e assim, no futuro próximo, poderiam extinguir a espécie Homo Sapiens.

Com o objetivo de controlar a parte da população geneticamente modificada, Trask, contando com o apoio técnico e financeiro do governo construiu as sentinelas, robôs gigantes responsáveis por capturar, prender ou até exterminar sistematicamente os/as mutantes. É oportuno notar que para uma sociedade que se diz democrática, a realidade e a ficção demonstram que ao menor sinal de alerta contra o status quo ou ao modo de produção vigente, as autoridades não relutam em encontrar meios para controlar ou limitar as ações de sua população. Podem chegar ao ponto de tratar parte dela como

9 Disponível em: https://exame.com/mundo/veja-na-integra-o-historico-discurso-de-martinluther-king/. Acesso em: 15/09/2020. 
sub-humana o não humana, por meio do medo ou ódio às diferenças, por vezes, semeando o pânico para atingir seus objetivos.

Em X-Men, o maior responsável por projetar a ideia de medo usada pelas autoridades é Erik Magnus Lehnsherr, um mutante conhecido como Magneto. Na sua primeira aparição nos quadrinhos, esse mutante com seus poderes de manipular metais, ataca uma base militar americana provocando um comportamento de desconfiança e mais adiante de temor nas pessoas. Aqui convém notar mais uma particularidade da estória: Magneto é um judeu polonês sobrevivente dos campos de concentração nazistas e, como já mencionado, mutante. Fatores que o fizeram ser discriminado durante toda a sua vida e, diferente do Professor Xavier, nenhum sofrimento causado pela exclusão despertou nele algum sentimento de resiliência ou perdão. Pelo contrário, Magneto de fato acreditava que o futuro pertencia aos mutantes e que a convivência pacífica era impossível diante da crueldade humana, e para isso todos os meios seriam necessários, inclusive a violência, para conseguir a emancipação dos/as mutantes.

Destacamos aos estudantes que o período compreendido entre 1950 e 1970, foi marcado pelos movimentos sociais em prol dos direitos civis do povo negro nos EUA. Algumas de suas figuras principais foram o pastor batista Martin Luther King Jr. e o intelectual mulçumano Malcon X. Apesar de ambos serem ícones dessa luta pela igualdade e pelo reconhecimento das pessoas negras como cidadãos e não apenas "pessoas de cor" excluídas socialmente, seus discursos divergiam em relação aos métodos utilizados para alcançar esse fim.

Como já havíamos destacado, Luther King pregava a igualdade por meio do diálogo e estratégias pacíficas para pressionar as autoridades a reconhecer a cidadania do povo negro. Malcon $X$, por seu turno, acreditava que tal reconhecimento iria vir de uma forma mais radical, com o uso da força/violência contra as pessoas brancas racistas. Seu discurso inflamado influenciou muitos negros e negras, até mesmo pessoas brancas. Cabe ressaltar que o pressuposto de tal revolta se refere ao processo histórico de injustiças, violências e segregação racial praticadas contra o povo negro, por e a favor de 
pessoas brancas. Malcon $\mathrm{X}$ e tantas outras lideranças dos movimentos sentiram o peso da indiferença.

Em face do exposto, é visível na construção imagética das personagens, associações com aspectos políticos nacionais e internacionais. A exemplo, o uso de cores específicas para caracterizar a luta do "bem contra o mal". Neste caso, o vermelho foi associado ao mal, ao russo e ao comunismo, enquanto as cores da bandeira dos EUA estampam as roupas dos heróis e heroínas. Diante disso, em 1991, ano da dissolução da URSS, os produtores da revista lançaram o vilão mais terrível até então, um russo sanguinário chamado Arkady Gregorivich Rossovich, usado pelo exército soviético como máquina de matar e, em sua forma geneticamente modificada, era conhecido como Ômega Red (Fim Vermelho, em tradução livre), numa explícita analogia a um estereótipo criado pelas autoridades estadunidenses para o enquadramento das forças militares soviéticas.

\section{Considerações finais}

Por fim, aborda-se como se deu a incursão dos/a autores(a) na experiência de planejamento e implementação de aulas de história utilizando HQs e cartoons como recursos didáticos e metodológicos nas aulas de história, no âmbito do PIBID/História com estudantes de $3^{\text {os }}$ anos do Ensino Médio. Nesse aspecto, faz necessário fazer algumas ponderações para elucidar os caminhos que decidimos percorrer no preparo e realização das aulas.

Uma primeira consideração é sobre o calendário da escola, a atividade foi planejada para o mês de setembro do ano de 2017. Todavia, com a aproximação do final do ano letivo, além dos procedimentos de recuperação realizadas nas turmas no final do bimestre letivo, algumas atividades postergadas pela escola tiveram de ser realizadas em um curto período de tempo, a exemplo, gincanas e jogos internos. Nesse aspecto, identificou-se comprometimento do calendário quanto as aulas de história, levando-nos a maior objetividade no desenvolvimento das ações dado que ainda não éramos professores(as) e dependíamos da autorização da professora supervisora. 
Outro fator que dificultou nossas atividades enquanto futuros professores(as) de história (até então bolsistas de Iniciação à Docência) foi a ausência de equipamentos ou condições adequadas na escola. Precisávamos em quase todas as aulas de equipamentos técnicos para projeção de imagens das HQs e cartoons, na ausência das HQs em estado físico, e também do uso de equipamentos de som, sendo estes imprescindíveis para o que havíamos planejado. Porém, apesar da escola dispor destes equipamentos, em função de ajustes no calendário letivo, os recursos técnicos foram usados em alguns momentos em outras atividades, dificultando maior ampliação do debate e exposição de conteúdos históricos até então programados nas reuniões de planejamento com a supervisora de área no espaço da escola e com o coordenador de área no âmbito da universidade.

As atividades programadas que priorizavam projeções de imagens com áudios, incursões dos/as estudantes na temática "Guerra Fria” por meio de produções individuais e em equipes, acabaram sendo reduzidas e, em alguns aspectos, suprimidas do planejamento, levando-nos ao uso expressivo de metodologias expositivas. Entretanto, os debates e reflexões sobre o tema aconteceram em sala de aula, não inviabilizando o que havia sido planejado na íntegra.

Notadamente, salienta-se que os/as estudantes do Ensino Médio já possuíam conhecimentos prévios sobre as $\mathrm{HQs}$ e cartoons, em larga medida também sobre a polarização pós Segunda Guerra Mundial. A discussão acerca da temática viabilizada pela professora supervisora da equipe em aulas anteriores e a disponibilidade de informações prévias permitiu que o conteúdo deixasse "de ser uma leitura distante, para poder dialogar com o estudante de forma objetiva, por meio de elementos linguagem verbal e não-verbal" (NEVES, 2012, p. 20).

Por fim, o trabalho fez uso da HQ X-Men numa abordagem envolvente do ponto de vista didático elevando as possibilidades de avanço no que tange uma melhor compreensão das questões geopolíticas exaustivamente discutidas em salas de aula, especialmente nas séries finais do Ensino Fundamental e Médio. Para tanto, o elemento visual tornou-se um importante 
instrumento na compreensão e andamento das reflexões acerca da temática em tela. Em contexto de Guerra, "a imagem é considerada como fruto de trabalho humano, pautado sobre códigos sociais, possuindo um caráter conotativo que toma as formas de ser e agir inseridas como mensagem" assinala Guerra (2011, p. 20).

Notou-se, nestas atividades uma melhor percepção e aproximação dos/as estudantes pela temática e pela metodologia utilizada, estes(as) desvelaram motivação pela linguagem na exposição da temática, bem como participação profícua ao ponto de nos surpreender com suas contribuições. Acreditamos, enfim, que a forma como se deu o nosso trabalho em sala de aula poderia ser ampliada no sentido de contemplar outras possibilidades de aprendizagem, desenvolvendo, assim, o potencial de leitura e novas formas de expressão dos/as estudantes, assim como ampliar repertórios de leituras e interpretação das experiências humanas no contexto histórico, os/as levando, decerto a elaboração de atividades, tais como: a produção de HQs e cartoons pelos estudantes nos mais variados contextos.

As HQs, de um modo geral, ressaltam os valores éticos e morais de sua sociedade, numa disputa pela construção de sentidos sobre a vida e os corpos humanos. Elas são instrumentos eficientes na transmissão de valores, viabilizado pela indústria cultural como bem explica (ADORNO; HORKHEIMER, 1971) no livro intitulado "A indústria Cultural". É interessante analisarmos que as HQs utilizadas contemplem tantos temas polêmicos sem suscitar qualquer tipo de revolta por parte das autoridades de forma imediata.

Acreditamos, por fim, que as atividades desenvolvidas e relatadas neste trabalho demonstraram que é possível, a partir de uma reflexão sistemática e aplicação planejada, incorporar a utilização de cartoons e HQs no ambiente escolar, estando os/as professores(as) atentos(as) a coerência e o contexto do que está sendo apresentado como possibilidade de ensino e aprendizagem histórica.

Faz-se necessário, ainda, destacar a importância da Lei de Diretrizes e Bases (LDB) de 1996 que permitiu que tais inovações pudessem acontecer dentro da sala de aula. Vergueiro e Ramos (2009), na obra intitulada: 
"Quadrinhos na Educação: da rejeição à prática", afirmam que ao apontar para a necessidade de inserção de novas linguagens e manifestações artísticas nos ensinos fundamental e médio, a LDB ampliou as possibilidades de utilização dos quadrinhos (aqui acrescentamos os cartoons) no ensino, mas, foram os Parâmetros Curriculares Nacionais (PCNs), lançados em 1997, que colocaram as HQs diretamente nas salas de aula.

Nesse contexto, consideramos que através do cartoon e HQs utilizadas neste escrito como conteúdos e metodologia de ensino, tornaram a sala de aula um espaço de veiculação do imaginário social do período da Guerra Fria, pois, destas duas linguagens emanaram outros elementos discursivos e visuais importantes na compreensão do embate ideológico, próprio do contexto histórico do objeto em discussão. Dessa forma, estes recursos se tornaram ferramentas viáveis e eficazes no processo de ensino e aprendizagem, uma vez que se aproximaram do cotidiano cultural dos estudantes, aliando entretenimento e conhecimento histórico.

Finalmente, agradecemos à Coordenação de Aperfeiçoamento de Pessoal do Ensino Superior (CAPES), pela concessão das bolsas PIBID (Iniciação à Docência, Supervisores e coordenador de área) que tornou possível a realização do subprojeto/História em duas escolas de Educação Básica da capital alagoana, nosso muito obrigado! Igualmente à equipe do PIBID/História, assim como os gestores e professores supervisores nas escolas que nos acolheram durante a implementação das ações do Subprojeto/História.

\section{Referências}

ADORNO, T. W.; HORKHEIMER, M. A indústria cultura. In: COHN, G (Org.). Comunicação e Indústria Cultural. São Paulo: Companhia Editora Nacional/EDUSP, 1971.

BEZERRA, A. A. Desafios na formação de professores de história no estado de Alagoas à luz de sua inserção no campo de trabalho. In: BAUMGARTEN, L. (Org.). História - Uma disciplina sob suspeita: reflexões, diálogos e práticas. Curitiba, PR, CRV, 2020, p. 59-72. 
BEZERRA, A. A. Professores de história e o PIBID enquanto espaço público de formação inicial e continuada. In: ANAIS da 70' Reunião Anual da SBPC - 22 a 28 de julho de 2018 - UFAL - Maceió / AL.

BEZERRA, A. A. O uso de projetos temáticos nas aulas de história: construção coletiva do processo de ensino e aprendizagem. Revista Labirinto. Ano XVI, v. 24, n. 2, p. 31-56, 2016.

BITTENCOURT, C. Ensino de História: fundamentos e métodos. São Paulo: Cortez. 2005.

BUTLER, J. Quadros de Guerra: quando a vida é passível de luto? 1ed. Rio de Janeiro: Civilização Brasileira, 2015.

BUTLER, J. Corpos em aliança e a política das ruas: notas para uma teoria performativa de assembleia. 1 ed., Rio de Janeiro: Civilização Brasileira, 2018.

BRASIL. Portaria nº 096, de 18 de julho de 2013, que regulamenta o Programa Institucional de Bolsas de Iniciação à Docência.

BRASIL. Lei de Diretrizes e Bases da Educação Brasileira (1996) - Redação dada pela lei $n^{\circ} 13.415$, de 2017.

BRASIL. Ministério da Educação. Secretaria de Ensino Fundamental. Parâmetros Curriculares Nacionais. História. Brasília, DF, MEC/SEF, 1998.

CERTEAU, M. A Escrita da História. Rio de Janeiro: Forense-Universitária, 1982.

COHN, G. (Org). Comunicação e indústria cultural. Cia Editora Nacional/Editora Universidade de São Paulo, 1971.

FENELON, D. R. Formação do profissional de História e a Realidade do Ensino. Tempos Históricos. v. 12, p.23-35, 2008.

GUERRA, F. V. Super Heróis e os conflitos sociais e políticos nos EUA (1961-1981). 2011. 229f. Dissertação (Mestrado em História). Programa de Pós-Graduação, Universidade Federal Fluminense, Rio de Janeiro, 2011.

HOBSBAWM, E. Era dos Extremos: o breve século XX: 1914-1991. São Paulo: Companhia das Letras, 1995.

HOPKINS, P. D. A sedução do normal: quem não quer ser um mutante? In: IRWIN, W. (Cood.). X-Men e a filosofia. São Paulo: Madras, 2009, p. 22-39.

IRWIN, W. (Coord.). X-Men e a filosofia. São Paulo: Madras, 2009.

MÉSZÁROS, I. Para além do capital: rumo a uma teoria da transição. 1 ed., São Paulo: Boitempo, 2011.

NEVES, S. C. A história em quadrinhos como recurso didático em sala de aula. (Monografia). Instituto de Artes da Universidade Aberta do Brasil. Tocantins, 2012. 
NÓVOA, A. Nada substitui um bom professor: propostas para uma revolução no campo da formação de professores. In. GATTI, B. A. et. al. (Org.). Por uma política nacional de formação de professores. São Paulo: EDUNESP, 2013. p.199-210

PEREIRA, N. M. \& SEFFNER, F. O que pode o ensino de história? Sobre o uso de fontes na sala de aula. Revista Anos 90. Porto Alegre, v. 15, n. 28, p.113128, dez. 2008.

Perfil socioeconômico e cultural dos(as) estudantes da UFAL [recurso eletrônico]: coleção UFAL e políticas públicas de gestão na educação superior. Maceió, EDUFAL/Proest, 2020.

RUBO, E. A, A. et al. Do núcleo de ensino ao PIBID: contribuição da Unesp à formação de professores. In. GATTI, B. A. et. al. (Org.). Por uma política nacional de formação de professores. São Paulo: EDUNESP, 2015, p.153170.

RÜSEN, J. O desenvolvimento da competência narrativa na aprendizagem histórica: uma hipótese ontogenética relativa à consciência moral. In: SCHMIDT, M. A.; BARCA, I.; MARTINS, E. R. (Orgs.) Jörn Rüsen e o ensino de História. Curitiba, PR, Editora da UFPR, 2010.

SANTIAGO, R. S. Cartoons e propaganda política. Revista Espacialidades, v. 2, n. 01, p. 01-16, 14 set. 2009.

PIMENTA, S. G.; LIMA, M. S. L. Estágios supervisionados e o Programa Institucional de Bolsas de Iniciação à docência: duas faces da mesma moeda? Revista Brasileira de Educação, v. 24, p. 1-20, 2019.

THE SIMPSONS. Lisa'sfirstword. Produção de Mark Kirkland e Jeff Martin. Estados Unidos: Fox Broadcasting Company, 1992

THE SIMPSONS Simpsons Tade. Produção de Joshua Sternin e Jeffrey Ventimilia. Estados Unidos: Fox Broadcasting Company, 1998.

VERGUEIRO, W.; RAMOS, P. (Org.) Quadrinhos na Educação: da rejeição à prática. São Paulo: Contexto, 2009.

\section{Sobre os autores}

\section{Antonio Alves Bezerra}

antonio.alves@ichca.ufal.br

Professor do curso de Licenciatura e do Programa de pós-graduação em História da Universidade Federal de Alagoas, Campus A.C. Simões. Mestre e doutor em História Social pela PUC/SP e coordenador do subprojeto PIBID/História da UFAL, líder do Grupo de Estudos Ensino, História e Docência (GEEHD) da UFAL/ICHCA. 


\section{José Augusto Ferreira da Silva}

jose.augusto.fs21@gmail.com

Mestrando em História pelo PPGH/UFAL e Licenciado em História pela UFAL/ICHCA, ex-bolsista do PIBID/UFAL/História (2017/2018) - Edital Capes no 61/2013. Membro do Grupo de Estudos Ensino, História e Docência (GEEHD) da UFAL/ICHCA.

\section{Roberta dos Santos Sodó}

robertasodo7@gmail.com

Graduanda em História - Licenciatura (UFAL/ICHCA), ex-bolsista PIBID (2017/2018 - Edital Capes $n^{\circ}$ 61/2013) e do Programa de Residência Pedagógica/PRP (2018/2020 - Edital Capes n 6/2018). Membro do Grupo de Estudos e Pesquisas em História, Gênero e Sexualidade (GEPHGS) e do Laboratório de Pesquisas e Práticas de Ensino de História (LAPPEHis). 